\title{
New mono- and di-branched derivatives of Kryptofix K22 with $N$-4-methoxyamino-3,5-dinitrobenzoyl substituents. Synthesis and properties
}

\author{
Madalina Tudose, ${ }^{\mathrm{a}}$ Miron T. Caproiu, ${ }^{\mathrm{b}}$ Florin D. Badea,,${ }^{\mathrm{c}}$ Georgian Nedelcu, ${ }^{\mathrm{d}}$ Petre Ionita, ${ }^{\mathrm{d}}$ \\ Titus Constantinescu, ${ }^{a}$ and Alexandru T. Balaban ${ }^{\mathrm{e}^{*}}$ \\ ${ }^{a}$ Institute of Physical Chemistry, 202 Spl. Independentei, Bucharest 060021, Romania \\ ${ }^{b}$ Center of Organic Chemistry, 202A Spl. Independentei, Bucharest 060023, Romania \\ ${ }^{c}$ University Politehnica, Organic Chemistry Department, 90 Panduri, Bucharest 050663, \\ Romania \\ ${ }^{d}$ University of Bucharest, Department of Organic Chemistry, Biochemistruy and Catalysis, \\ Bucharest 011061, Romania \\ ${ }^{e}$ Texas A\&M University at Galveston, Department of Marine Sciences, P. O. Box 1675, \\ Galveston TX 77553-1675, USA \\ E-mail: balabana@tamug.edu
}

DOI: $\underline{\text { http://dx.doi.org/10.3998/ark.5550190.0012.228 }}$

\begin{abstract}
Starting from the Kryptofix 22 azacrown compound, mono- and di-branched derivatives have been synthesized, by coupling with one or two 4-chloro-3,5-dinitrobenzoyl chloride units and then substituting the chlorine(s) on the aromatic ring(s) with methoxyamine. The two new compounds were characterized by IR, NMR, and UV-Vis spectra; they are soluble in organic solvents, yielding a yellow color, which is changing to blue in the presence of a base (such as alkali metal hydroxides), thus acting as colorimetric chemosensors. The ratios of complexation and extraction constants with alkali metal cations were measured.
\end{abstract}

Keywords: Kryptofix K22 derivatives, UV-Vis, ionophoric properties

\section{Introduction}

Supramolecular chemistry deals with non-covalent interactions between two or more chemical species. ${ }^{1}$ After the award of the Nobel Prize in 1987 to Lehn, Cram and Pedersen, as an acknowledgement of their studies regarding supramolecular systems, ${ }^{2}$ this area of research has seen a tremendous development. ${ }^{3}$ Significant advances have been achieved in many classical 
branches of chemistry, such as biological, physical, organic, and analytical chemistry; moreover, frontier sciences have been developed. ${ }^{4-6}$

Crown ethers ${ }^{7}$ have found major applications only after supramolecular chemistry has developed as science. Thus, their remarkable property to solubilize inorganic cations in organic media or to transfer them between two immiscible phases, found immediate application in analytical chemistry and phase-transfer catalysis., 8

Kryptofix 22, an azacrown ether, namely 1,4,10,13-tetraoxa-7,16-diazacyclooctadecane, has been used widely as a starting material to obtain new crown derivatives with interesting or improved properties; the presence of two secondary amino groups made possible the derivatization of Kryptofix 22, thus, by attaching one or two moieties to Kryptofix 22, two derivatives are possible, a mono- and a di-branched compound. ${ }^{10-18}$

Among the numerous derivatives obtained from Kryptofix 22 we can mention those containing polynitrophenyl derivatives, hydrazyl radicals, azobenzene, or fluorescent moieties. ${ }^{10-}$ 15 All these derivatives showed interesting properties and they can be used as sensors and probes in different physical-chemical processes. Studies regarding recognition, binding, or transport of several species led to the development of materials that can act as sensors; for example, chromogenic crown ethers have been successfully used as selective optical sensors for some of the alkali cations. ${ }^{15-20}$

$\mathrm{N}$-Alkoxy-polynitroanilines have acid-base and redox properties; thus, in an acid-base reaction, they change their color according to the $\mathrm{pH}$ (working as $\mathrm{pH}$ indicators), and in redox processes they generate persistent $\mathrm{N}$-alkoxyaminyl free radicals. ${ }^{21-23}$ Attaching such moieties to Kryptofix 22 results in new compounds which may have interesting analytical applications. In the present paper we report two new crown compounds derived from Kryptofix 22, and their complexation properties towards alkali metal cations.

\section{Results and Discussion}

\section{Synthesis}

4-Chloro-3,5-dinitrobenzoic acid $\mathbf{1}$ was converted into the corresponding acid chloride $\mathbf{2}$ by reaction with thionyl chloride (Scheme 1). This reaction is fast in the presence of a small amount of DMF as catalyst. Compound 2 reacted easily with Kryptofix 22: depending on the molar ratio between these reactants, compounds $\mathbf{3}$ or $\mathbf{4}$ were obtained. Although compound $\mathbf{2}$ has two reactive groups which may react with Kryptofix 22 (the $-\mathrm{COCl}$ and the $-\mathrm{Cl}$ substituent, both activated by the presence of the two nitro groups on the aromatic ring) the acid chloride group is far more reactive and allows the chemoselective synthesis of compounds $\mathbf{3}$ and $\mathbf{4}$. These compounds were not isolated but the reaction mixture was directly treated with the supernucleophile methoxyamine ${ }^{24}$ affording the final compounds 5 and $\mathbf{6}$ (Scheme 1). The structures of the new compounds 5 and $\mathbf{6}$ were confirmed by spectroscopic methods. Thus, in the IR spectra stretchings due to the carbonyl group appeared at $\sim 1630 \mathrm{~cm}^{-1}$, the nitro groups at 
$\sim 1540$ and $1340 \mathrm{~cm}^{-1}$, the ether groups at $\sim 1100 \mathrm{~cm}^{-1}$ and the aromatic ring at $\sim 3070 \mathrm{~cm}^{-1}$. In the ${ }^{1} \mathrm{H}-\mathrm{NMR}$ spectra, the $\mathrm{NH}$ proton appeared between $10-11 \mathrm{ppm}$, the aromatic hydrogens at 8.2$8.3 \mathrm{ppm}$, the methoxy group at 3.6-3.8 ppm, and the $\mathrm{CH}_{2} \mathrm{O}$ from the crown moiety around 3.3$3.8 \mathrm{ppm}$. In the ${ }^{13} \mathrm{C}-\mathrm{NMR}$ spectra, the carbonyl appeared at about 160-170 ppm, the C-atoms from the crown moiety around $45-50 \mathrm{ppm}$, and the methoxy groups at $\sim 63 \mathrm{ppm}$.

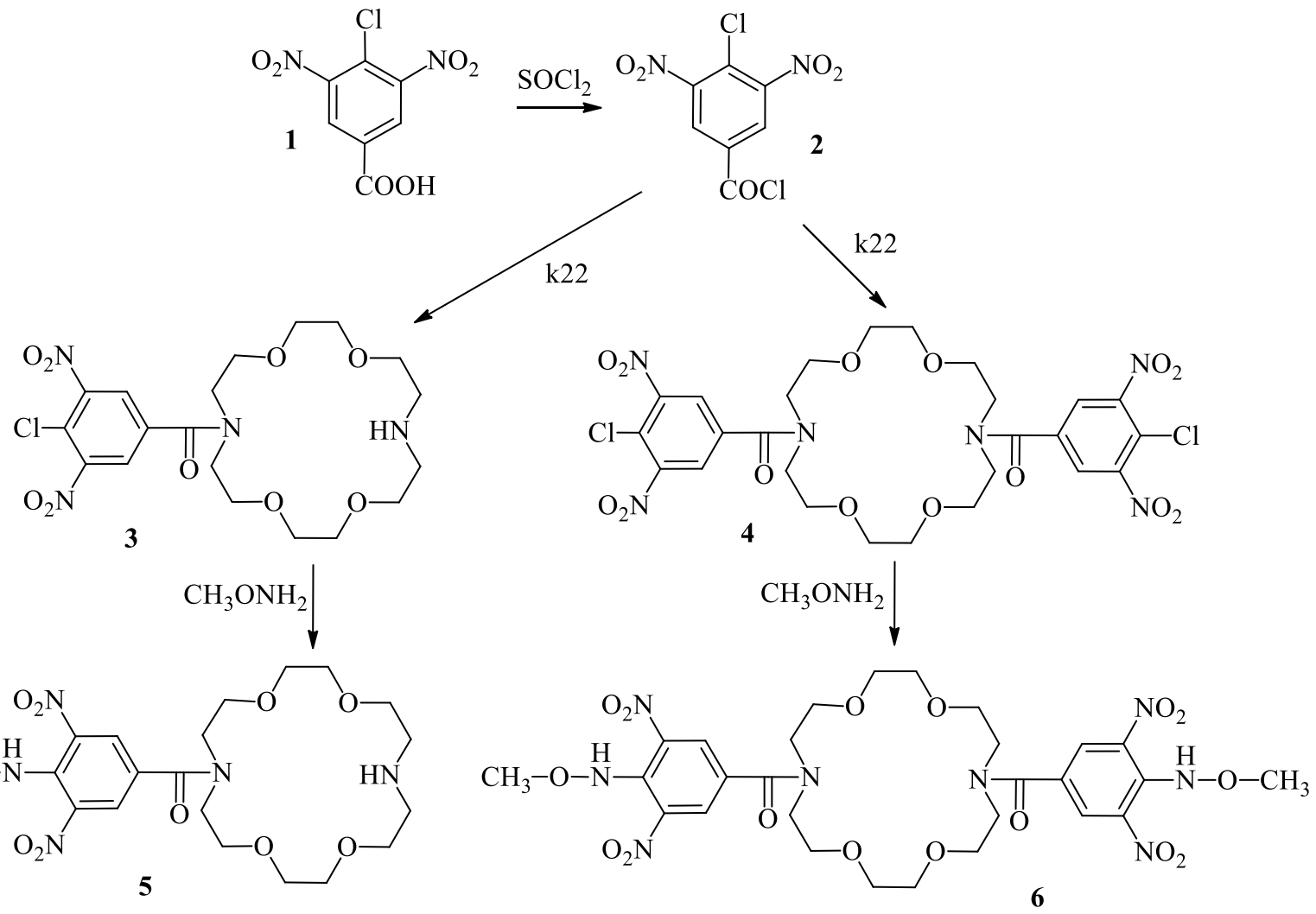

Scheme 1. Synthesis of compounds 5 and $\mathbf{6}$.

\section{Acid-base characteristics of compounds (5) and (6)}

The proton of the methoxyamino group is quite acidic due the influence of the adjacent oxygen atom and dinitrobenzene ring. Previous work had shown that the value of $\mathrm{p} K_{\mathrm{a}}$ for similar compounds lies between 5 and 10, depending on the chemical structure (i.e. $N$-methoxy-2,4,6trinitroaniline has a $\mathrm{p} K_{\mathrm{a}}$ value of 5.0, while $N$-methoxy-2,4-dinitroaniline has a $\mathrm{p} K_{\mathrm{a}}$ value of 9.2). ${ }^{21-23}$ The most important fact about such compounds is that they change color as the $\mathrm{pH}$ changes; this behavior could be used for developing crown compounds which have different colors at different $\mathrm{pH}{ }^{10,11,25}$ Compounds $\mathbf{5}$ and $\mathbf{6}$ are yellow compounds as solids or dissolved in appropriate organic solvents, and they instantly become blue in the presence of a base. Thus, $\mathbf{5}$ has an absorption maximum at $395 \mathrm{~nm}$ in methanol (yellow), while addition of an alkali hydroxide turns it to blue, with an absorption maximum at $600 \mathrm{~nm}$; similarly, 6 absorbs at 390 $\mathrm{nm}$ in methanol (yellow), while addition of an alkali hydroxide turns it to blue, with an 
maximum at $605 \mathrm{~nm}$ (Table 1). The difference between $\lambda_{\max }\left(\Delta \lambda_{\max }\right)$ in the acid-base process (equation 1) is high (Table 1), recommending the derivatives 5 and $\mathbf{6}$ for analytical applications, such as indicators for titrations in non-aqueous media (the compounds also having high epsilon values) (Table 1).

$$
\mathrm{HA}+\mathrm{B}: \rightarrow \mathrm{BH}^{+}+\mathrm{A}^{-}
$$

where HA is 5 or 6.

In equation (1) the base can be organic or inorganic anions $\left(\mathrm{HO}^{-}, \mathrm{HCO}_{3}{ }^{-}, \mathrm{CO}_{3}{ }^{2-}\right.$, methoxide, phenoxide, etc.), as well as neutral organic bases (amines) and/or basic amino acids (arginine, lysine).

Table 1. Spectral characteristics of compounds 5 and $\mathbf{6}$ in methanol

\begin{tabular}{|c|c|c|c|}
\hline \multirow{2}{*}{ Compound } & \multicolumn{2}{|c|}{$\lambda_{\max }(\mathrm{nm}) ; \quad \log \varepsilon\left(\mathrm{mol}^{-1} \mathrm{~L} \mathrm{~cm}^{-1}\right)$} & \multirow{2}{*}{$\Delta \lambda_{\max }{ }^{\mathrm{b}}(\mathrm{nm})$} \\
\hline & acid form & anion form ${ }^{\mathrm{a}}$ & \\
\hline 5 & $395 ; 3.99$ & $600 ; 4.00$ & 205 \\
\hline 6 & $395 ; 4.14$ & $605 ; 3.87$ & 210 \\
\hline
\end{tabular}

ain the presence of triethylamine. ${ }^{\mathrm{b}} \Delta \lambda_{\max }=\lambda_{\max }$ (anion) $-\lambda_{\max }$ (acid).

This color change is due to the formation of the corresponding anion with a delocalized system involving the nitro groups. The process is reversible: by adding an acid, the yellow color is restored. Unfortunately, the low solubility of compound $\mathbf{5}$ in water or in a mixture of watermethanol did not allow us to determine the $\mathrm{p} K_{\mathrm{a}}$ values, however these are probably around 8 , because a buffer solution with $\mathrm{pH}=8$ or even diluted sodium hydrogen carbonate induces the color change, from yellow to bright blue.

\section{Ratio of complexation and extraction constants for compounds (5) and (6)}

Compound (5). For compound 5 the extraction method, using a biphasic liquid-liquid system (organic solvent immiscible with water) was employed in order to measure the ratio of complexation between the crown moiety and the alkali metal cations $\mathrm{Li}^{+}, \mathrm{Na}^{+}$and $\mathrm{K}^{+}$; this method also allows the determination of the extraction constant ${ }^{26-28}$ with some limitations. The overall process of transferring the cation from an aqueous solution into the organic phase is described below (Scheme 2). For conciseness, compound 5 is written in equation (2) as $L_{\text {org. }}$. 


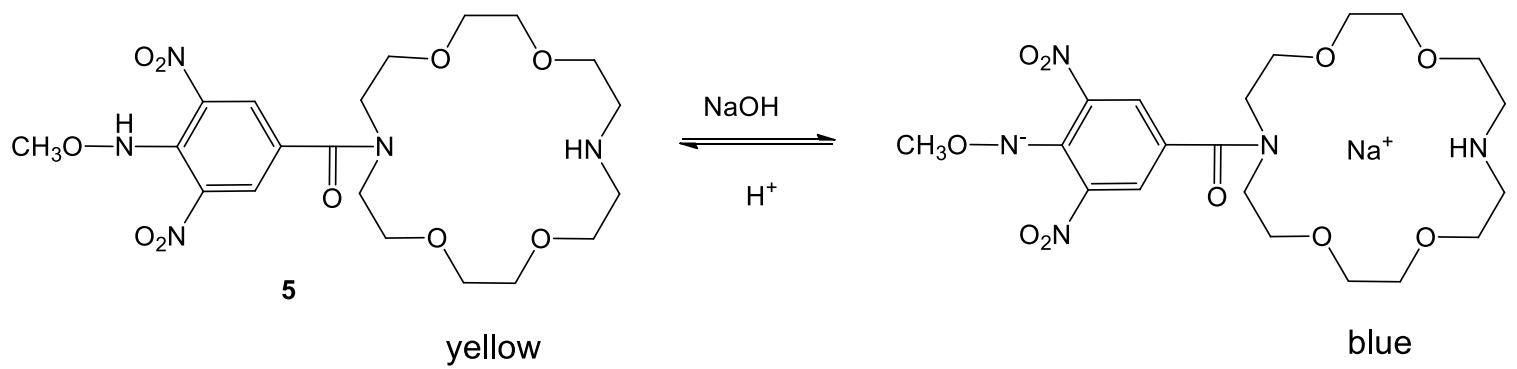

Scheme 2. The complexation process for compound 5 .

Equation (2) shows the complexation reaction, in which the alkali cation $\left(M^{+}\right)$is transferred into the organic phase as supramolecular complex. The concentration of this complex is easily measured spectrometrically, due to the large bathochromic shift; however, more than one cation might be complexed by the crown moiety, so equation (2) has been used for the complexation process, where $L_{o r g}$ is the ligand (the crown compound) and $n$ is the number of cations complexed by the ligand.

$$
\mathrm{L}_{\mathrm{org}}+n \mathrm{M}^{+}{ }_{\mathrm{aq}} \rightleftharpoons\left[\mathrm{L} . . . n \mathrm{M}^{+}\right]
$$

The extraction constant $K_{e x}$ is given by equation 3 .

$$
K_{e x}=\frac{\left[\mathrm{L} \ldots n \mathrm{M}^{+}\right]_{\mathrm{org}}}{\left[\mathrm{M}^{+}\right]^{\mathrm{n}}{ }_{\mathrm{aq}} \times[\mathrm{L}]_{\mathrm{org}}}
$$

In logarithmic form, equation 3 becomes equation 4 which can be converted into a first-order equation $(y=a x+b)$, taking into account that in practice the concentration of the cation in water does not change (it is about three orders of magnitude higher than the concentration of the ligand, see Experimental). The graphical representation of equation (4) allowed the simultaneous determination of the complexation ratio $n$ and the extraction constant $\log K_{e x}$ :

$$
\log \left[\mathrm{L} \ldots n \mathrm{M}^{+}\right]_{\text {org }}=n \log \left[\mathrm{M}^{+}\right]_{\text {aq }}+\log [\mathrm{L}]_{\text {org }}+\log K_{\text {ex }}
$$

Figure 1 shows the graphical representation for the alkali metal cations $\mathrm{Li}^{+}, \mathrm{Na}^{+}$, and $\mathrm{K}^{+}$, where one can note the slope of the first-order equation as $n=1$ (for all graphs, the correlation coefficient $r$ is between 0.95 and 0.99 ). This means that each crown moiety complexes only one cation, so the ratio of complexation is in all cases one-to-one. As mentioned before, it was also possible to determine the extraction constant $\log K_{e x}$, and the values obtained are 6.5, 6.8, and 7.4 for $\mathrm{K}^{+}, \mathrm{Na}^{+}$, and $\mathrm{Li}^{+}$, respectively. At first sight these values seem in reverse order, however this can be explained by the fact that the amidic nitrogen atom is unable to bind the alkali cation while the amino nitrogen atom binds it weakly compared with the oxygen ones and, moreover, 
the flexibility of the crown moiety may have a great influence, probably tailoring a size for the cavity more appropriate to $\mathrm{Li}^{+}$(it is well known that for the macrocycle 12-crown-4, containing the same number of oxygen atoms, the lithium cation fits best), as literature data showed regarding the cation diameters (Table 2). In Table 2 the experimental results demonstrate the same ratio of complexation $(1: 1)$, the influence of the extraction constants $\left(K_{e x}\right)$ decreases as a function of cation diameters $\left(K_{e x} \mathrm{Li}^{+}>K_{e x} \mathrm{Na}^{+}>K_{e x} \mathrm{~K}^{+}\right)$, thus validating the supposition that the macrocyclic moiety of compound 5 can be regarded as similar to that of 15-crown-5 (1,7-2,2 $\AA$ ); ${ }^{29,30}$ in this way one can explain why compound 5 may complex the potassium cation (which has a diameter of 2,66 $\AA,{ }^{29,30}$ compatible with 18-crown-6). ${ }^{1,9,30,31}$

Table 2. Ratio of complexation $(n)$ and extraction constant $\left(\log K_{e x}\right)$ for 5 and $\mathbf{6}$ with alkali metal cations $\mathrm{Li}^{+}, \mathrm{Na}^{+}$, and $\mathrm{K}^{+}$(cation diameters after ref. ${ }^{29}$ )

$$
\mathrm{Li}^{+}
$$

$$
\mathrm{Na}^{+}
$$

$\mathrm{K}^{+}$

Compound Cation diameter $1.36 \AA \quad$ Cation diameter $1.94 \AA \quad$ Cation diameter $2.66 \AA$

\begin{tabular}{ccccccc} 
& $n$ & $\log K_{e x}$ & $n$ & $\log K_{e x}$ & $N$ & $\log K_{e x}$ \\
\hline $\mathbf{5}$ & 0.82 & 7.4 & 0.91 & 6.8 & 1.05 & 6.5 \\
$\mathbf{6}$ & 2.3 & - & 2.2 & - & 2.2 & - \\
\hline
\end{tabular}

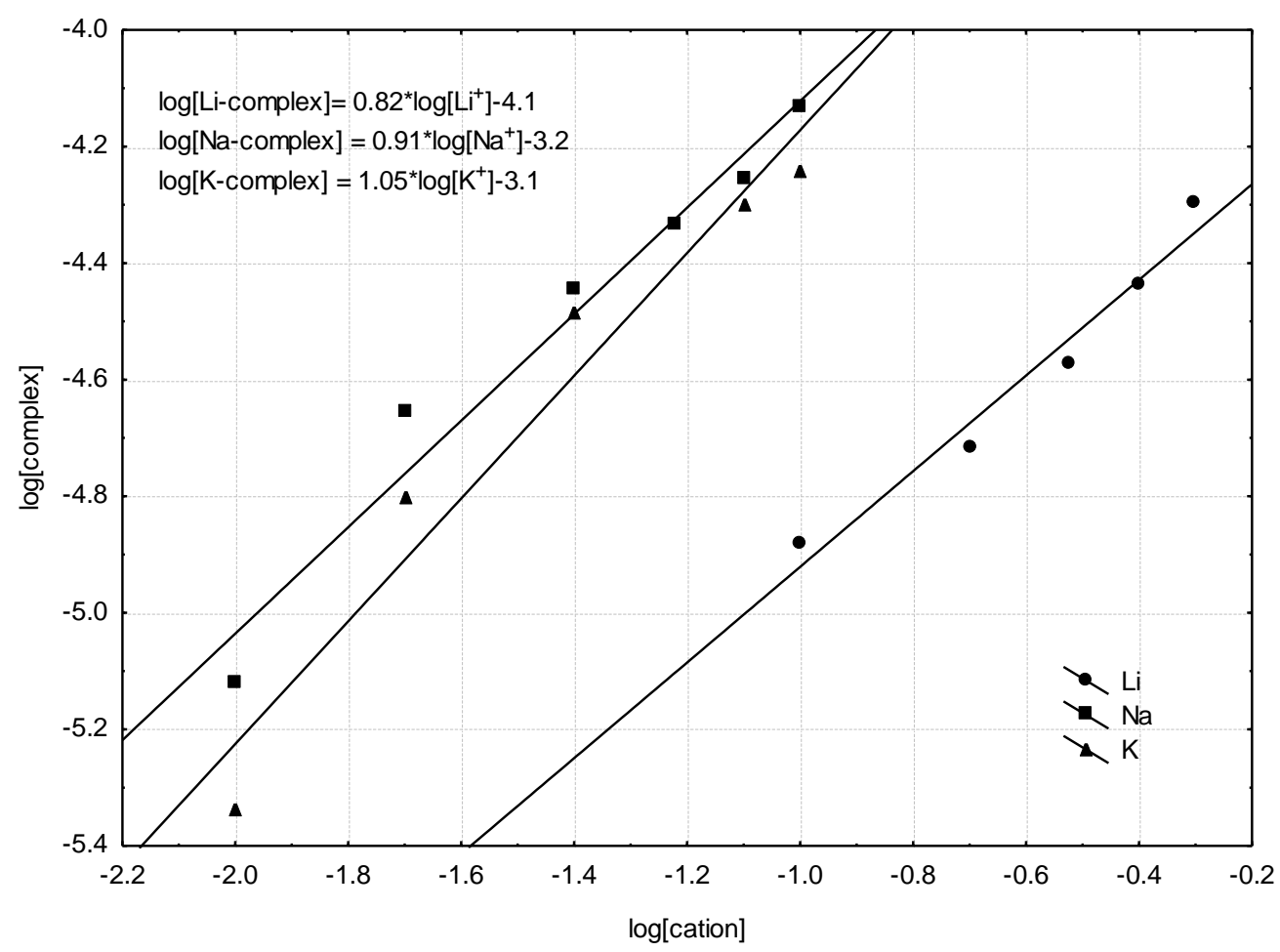

Figure 1. Graphical representation of $\log [$ complex $]$ vs. $\log \left[\mathrm{M}^{+}\right]$for measuring the ratio of complexation. 
Compound (6). Similarly to compound 5, compound 6 changes its color in basic media, and we exemplify this behavior by showing the UV-Vis spectra recorded in 1,2-dichloroethane (dashed line, $\lambda_{\max }=400 \mathrm{~nm}$ ) and aqueous alkali metal hydroxide (solid line, $\lambda_{\max }=595 \mathrm{~nm}$ ), in Figure 2.

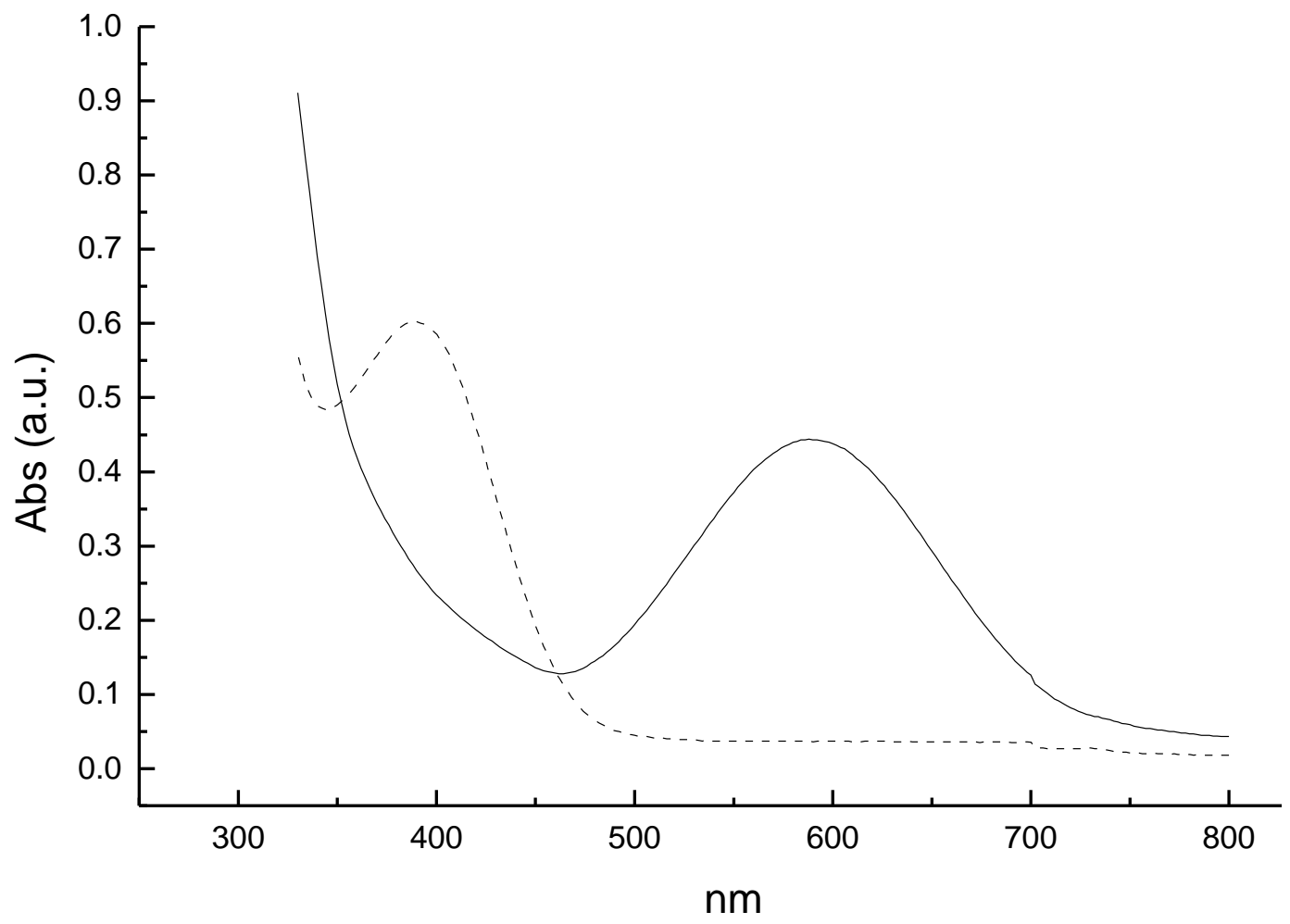

Figure 2. UV-Vis spectra of 6 in 1,2-dichloroethane (dashed line) and in aqueous sodium hydroxide solution (solid line).

For compound $\mathbf{6}$ it was not possible to use the same biphasic extraction procedure, because compound 6 forms a dianion that unexpectedly is water-soluble. In this case, for measuring the ratio of complexation, we prepared the solid complexes of $\mathbf{6}$ with the alkali metal cations $\mathrm{Li}^{+}$, $\mathrm{Na}^{+}$, and $\mathrm{K}^{+}$(see Experimental); then, using a back titration method ${ }^{21}$ (see Experimental), we determined the mass of compound $\mathbf{6}$ present in the solid complex, and in this indirect way the ratio of complexation (Table 2). The experimental data (Table 2) demonstrated that the ratio of complexation between cations $\left(\mathrm{Li}^{+}, \mathrm{Na}^{+}, \mathrm{K}^{+}\right)$and compound 6 is 2:1. Unlike compound 5, compound 6 with two amidic nitrogen atoms has a complexation ability due only to the four oxygen atoms (comparable to that of 12-crown-4, which has a diameter of $1.2 \AA$ ), ${ }^{1}$ but its geometry can also accommodate larger cations.

In order to obtain additional structural information about compounds $\mathbf{5}$ and $\mathbf{6}$, optimized structures of these molecules were calculated using the HyperChem molecular modeling package. ${ }^{32}$ 


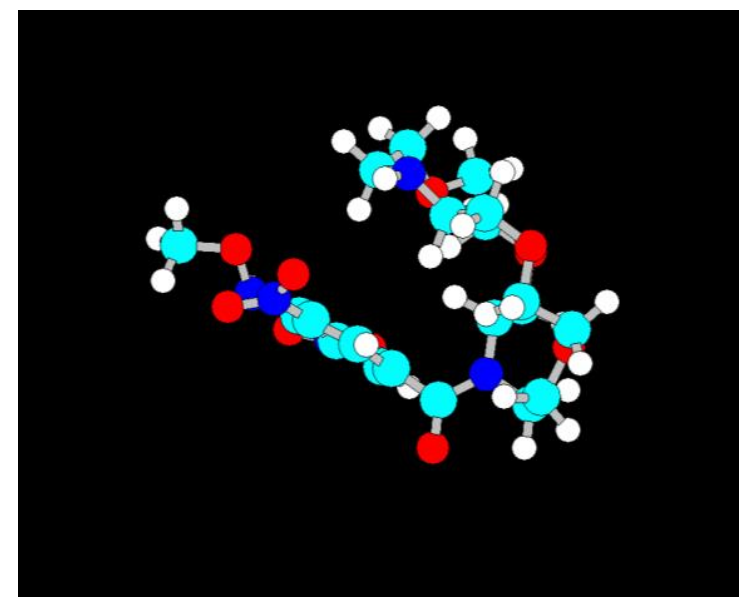

(a)

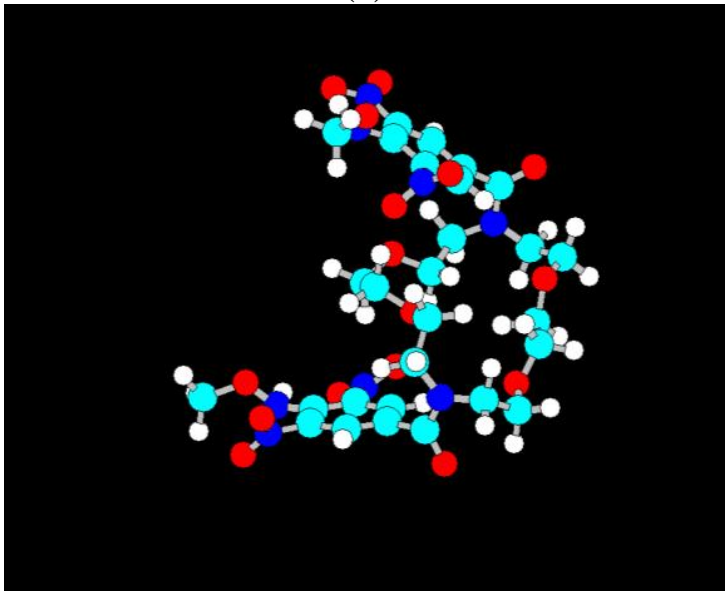

(c)

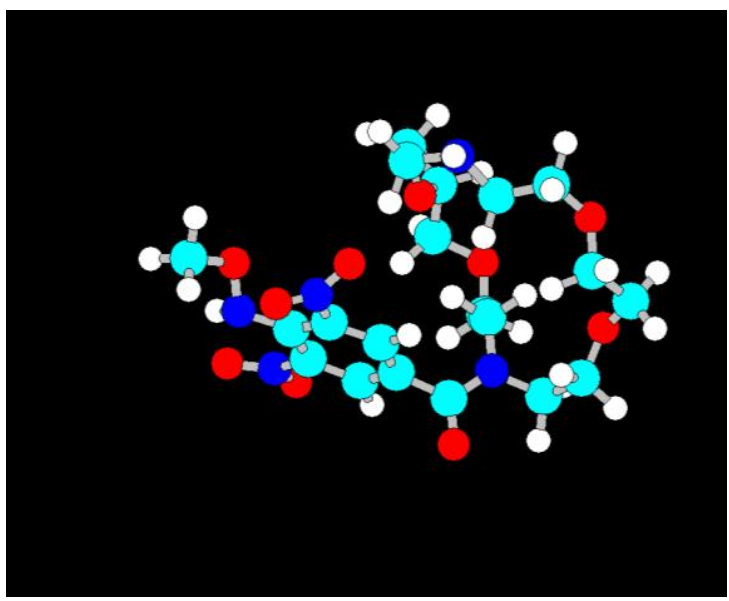

(b)

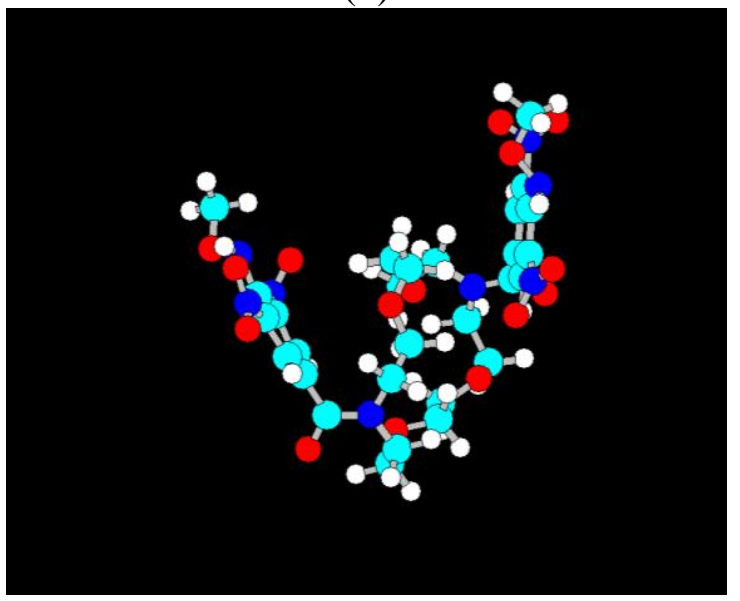

(d)

Figure 3. Optimized structures of compound $5(a, b)$ and $6(c, d)$.

In Figure 3 we note that for compound $\mathbf{5}$ the crown ether moiety is oriented towards the aromatic ring, leaving only one possibility for the cation to access the macrocyclic cavity. The same feature is noticed for compound $\mathbf{6}$, where the two aromatic rings practically face each other.

Table 3 shows the atomic charges of the hetero-atoms from the crown ether moiety obtained using the semi-empirical method AM1 ${ }^{32}$ For compound 5, as expected, the nitrogen and oxygen atoms from the crown ring are negatively charged, being better able to complex positively charged cations. Compound $\mathbf{6}$ is significantly different: the two nitrogen atoms are now positively charged, a fact that interferes with the complexation process. One can thus understand the lower complexation capacity of this derivative. 
Table 3. Atomic charge (AC) of the nitrogen $(\mathrm{N})$ and oxygen $(\mathrm{O})$ atoms in the Kryptofix $\mathrm{K} 22$ derivatives $\mathbf{5}$ and $\mathbf{6}$

\begin{tabular}{ccccccc}
\hline $\mathrm{AC}$ & $\mathrm{N} 1$ & $\mathrm{O} 1$ & $\mathrm{O} 2$ & $\mathrm{O} 3$ & $\mathrm{O} 4$ & $\mathrm{~N} 2$ \\
\hline $\mathbf{5}$ & -0.316 & -0.268 & -0.279 & -0.271 & -0.302 & -0.301 \\
$\mathbf{6}$ & 0.094 & -0.191 & 0.005 & -0.089 & -0.322 & 0.282 \\
\hline
\end{tabular}

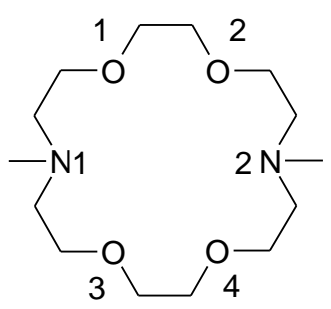

\section{Conclusions}

Two new azacrown derivatives have been synthesized and characterized. They are derived structurally from Kryptofix-22 (diaza-18-crown-6-ether) with one or two 4-methoxyamino-3,5dinitrobenzoyl groups (compounds $\mathbf{5}$ and $\mathbf{6}$, respectively). The main property of these compounds, besides their ability for complexing alkali metal cations, is their color transition, from yellow in acidic or neutral media to blue in alkaline media. This behavior may recommend them for use as colorimetric chemosensors in many physical-chemical processes where $\mathrm{pH}$ changes occur.

\section{Experimental Section}

General. All chemicals and materials (from Sigma-Aldrich) and solvents (from Chimopar) were used as received. UV-Vis spectra were recorded in various solvents at ambient temperature (20$22{ }^{\circ} \mathrm{C}$ ) on a UVD-3500 spectrometer; IR spectra were recorded on a FT-IR Bruker Vertex 70 spectrometer; ${ }^{1} \mathrm{H}$ - and ${ }^{13} \mathrm{C}-\mathrm{NMR}$ spectra were recorded on a Varian Inova-400 spectrometer.

\section{Synthesis}

4-Chloro-3,5-dinitrobenzoyl chloride (2). 4-Chloro-3,5-dinitrobenzoic acid 1 (1 g, 4 mmol) was suspended in 1,2-dichloroethane $(40 \mathrm{~mL})$ and heated at reflux for $40 \mathrm{~min}$ with $1 \mathrm{~mL}$ of $\mathrm{SOCl}_{2}(1 \mathrm{~mL})$ and DMF (3 drops). Removal of the solvent and unreacted $\mathrm{SOCl}_{2}$ under vacuum yielded 2 almost quantitatively. ${ }^{25,33}$

Compound (5). 4-Chloro-3,5-dinitrobenzoyl chloride ( $0.5 \mathrm{~g}, 2 \mathrm{mmol})$ and Kryptofix 22 (0.53 g, $2 \mathrm{mmol}$ ) were dissolved in $\mathrm{CH}_{2} \mathrm{Cl}_{2}(30 \mathrm{~mL})$ and the reaction mixture left for $1 \mathrm{~h}$, then $\mathrm{Et}_{3} \mathrm{~N}(1$ $\mathrm{mL}$ ) was added, and the mixture left for another hour. After that, methoxyamine hydrochloride 
$(0.255 \mathrm{~g}, 3 \mathrm{mmol})$ was added together with $\mathrm{Et}_{3} \mathrm{~N}(2 \mathrm{~mL})$, and the reaction mixture was left overnight. Next day $\mathrm{CH}_{2} \mathrm{Cl}_{2}(50 \mathrm{~mL})$ was added and the final solution was extracted with dilute hydrochloric acid $(100 \mathrm{~mL})$, followed by aqueous $\mathrm{NaHCO}_{3}(100 \mathrm{~mL})$ and water $(100 \mathrm{~mL})$, and the organic layer was dried over anhydrous $\mathrm{Na}_{2} \mathrm{SO}_{4}$, the solid filtered off and the solvent was removed. The residue was purified by chromatography on silica gel using $\mathrm{CH}_{2} \mathrm{Cl}_{2} / \mathrm{MeOH} 9 / 1$ as eluent; ca. $40 \%$ yield, yellow solid, mp 85-86 ${ }^{\circ} \mathrm{C}$; Anal. Found: C, 48.12; H, 6.21; N, 13.62\% $\mathrm{C}_{20} \mathrm{H}_{31} \mathrm{~N}_{5} \mathrm{O}_{10}$ requires C, 47.90; H, 6.23; N, 13.96\%; IR (ATR, $\mathrm{cm}^{-1}$ ): 3357, 3071, 2924, 2856, 1722, 1632, 1540, 1467, 1347, 1262, 1194, 1104, 1067, 908, 799, 730, 716, 648, 561, 456.

${ }^{1} \mathrm{H}-\mathrm{NMR}\left(\mathrm{CDCl}_{3}, \delta \mathrm{ppm}\right): 9.98$ (s, $\left.1 \mathrm{H}, \mathrm{H}-\mathrm{N}\right), 8.31$ (s, 2H, H-3, H-5), 3.76 (s, 3H, CH ), 3.80-3.40 (m, 24H, H-crown ether); ${ }^{13} \mathrm{C}-\mathrm{NMR}\left(\mathrm{CDCl}_{3}, \delta \mathrm{ppm}\right): 167.6(\mathrm{C}-8) ; 138.56(\mathrm{C}-1)$; 137.1 (C-2, C6); $129.6(\mathrm{C}-3, \mathrm{C}-5) ; 127.3(\mathrm{C}-4) ; 70.8\left(\mathrm{CH}_{2}\right.$, crown ether $) ; 69.6\left(\mathrm{CH}_{2}\right.$, crown ether $) ; 63.8\left(\mathrm{CH}_{2}\right.$, crown ether).

Compound (6). 4-Chloro-3,5-dinitrobenzoyl chloride (0.5 g, $2 \mathrm{mmol})$ and Kryptofix 22 (0.26 g, $1 \mathrm{mmol})$ of were dissolved in $\mathrm{CH}_{2} \mathrm{Cl}_{2}(30 \mathrm{~mL})$ and the reaction mixture was left for $1 \mathrm{~h}$, then $\mathrm{Et}_{3} \mathrm{~N}(2 \mathrm{~mL})$ was added, and the mixture was left for another hour. After that, methoxyamine hydrochloride $(0.255 \mathrm{~g}, 3 \mathrm{mmol})$ was added together with $\mathrm{Et}_{3} \mathrm{~N}(2 \mathrm{~mL})$, and the reaction mixture was left overnight. Next day $\mathrm{CH}_{2} \mathrm{Cl}_{2}(30 \mathrm{~mL})$ was added to the mixture and the solution was extracted with dilute hydrochloric acid $(100 \mathrm{~mL})$, followed by aqueous $\mathrm{NaHCO}_{3}(100 \mathrm{~mL})$ and water $(100 \mathrm{~mL})$, and the organic layer was dried over anhydrous $\mathrm{Na}_{2} \mathrm{SO}_{4}$, the solid filtered off and the solvent removed. The residue was purified by chromatography on silica gel using $\mathrm{CH}_{2} \mathrm{Cl}_{2} / \mathrm{MeOH} 9 / 1$ as eluent; ca. $60 \%$ yield, yellow solid, mp 169-170 ${ }^{\circ} \mathrm{C}$; Anal. Found: C, 45.09; H, 4.85; N, 15.02\% $\mathrm{C}_{28} \mathrm{H}_{36} \mathrm{~N}_{8} \mathrm{O}_{16}$, requires C, 45.41; H, 4.90; N, 15.13\%; IR (ATR, $\left.\mathrm{cm}^{-1}\right)$ : 3288, 3077, 2951, 2904, 2867, 2814, 1628, 1553, 1458, 1433, 1336, 1270, 1187, 1115, 1098, 1059, 972, 908, 622, 454; ${ }^{1} \mathrm{H}-\mathrm{NMR}\left(\mathrm{CDCl}_{3}, \delta \mathrm{ppm}\right): 10.80$ (bs, 2H, H-N), 8.22 (s, 4H, H-3, H-5), 3.61(s, 6H, H $\left.{ }_{3} \mathrm{C}-\mathrm{O}\right), 3.78-3.52$ (m, 16H, H-crown ether), 3.33 (bs, 8H, H-8, H-13, H-crown ether); ${ }^{13} \mathrm{C}-\mathrm{NMR}\left(\mathrm{CDCl}_{3}, \delta \mathrm{ppm}\right): 167.1$ (C-7); 148.8 (C-2, C-6); 139.0 (C-1); 127.1 (C-3, C-5); 70.1 (C-10, C-11); 68.6 (C-9, C-12); 62.9 ( $\left.\mathrm{CH}_{3}-\mathrm{O}\right)$; 50.0 (bs, C-8, C-13); 46.4 (bs, C-8, C-13).

\section{Extraction constants and ratio of complexation measurements}

For compound 5 the well-known extraction method was employed; thus, M a solution of 5 ( $3 \mathrm{~mL}$ $\left.4 \times 10^{-4}\right)$ in 1,2-dichloroethane was shaken with aqueous alkali metal hydroxide solution $(3 \mathrm{~mL})$ of $\mathrm{Li}^{+}$(concentration range between 0.1-0.5 M), $\mathrm{Na}^{+}$(concentration range between 0.02-0.1 M), or $\mathrm{K}^{+}$(concentration range between 0.01-0.1 M). After phase separation, the organic layer was transferred into a standard quartz vial and the absorbance was measured at $600 \mathrm{~nm}$ (it was usually necessary to clarify the cloudy solution using a small amount of anhydrous $\mathrm{Na}_{2} \mathrm{SO}_{4}$ ). It was easily noted that the organic layer changed its color (also, the aqueous layer became slightly blue, due probably to the high concentration of the base which may dissolve traces of crown compound). Various concentrations of the aqueous solution led to different values of absorption, and graphical representation of these values allowed the simultaneous determination of the extraction constants and ratios of complexation. 
For the complexes of compound $\mathbf{6}$ the stoichiometry was estimated as follows: solid complexes of compound 6 with $\mathrm{Li}^{+}, \mathrm{Na}^{+}$, and $\mathrm{K}^{+}$were obtained by mixing 6 with excess cations $\mathrm{Li}^{+}, \mathrm{Na}^{+}$, and $\mathrm{K}^{+}$(as hydroxides) in methanol then precipitation of the blue complex salts with $\mathrm{CH}_{2} \mathrm{Cl}_{2}$ and hexane. These complexes were then dissolved in water and titrated with hydrochloric acid $1 \mathrm{~N}$, measuring the concentration of $\mathbf{6}$ spectrometrically.

\section{References}

1. Weber, E.; Toner,Y. L.; Goldenberg, Y.; Vögtle, F.; Leidler, D. A.; Stoddart, Y. F.; Bartsch, R. A.; Liotta, C. L. Crown Ethers and Analogs. Wiley-Interscience, New York, 1989.

2. Cram, D. J. Angew. Chem., Int. Ed. Engl. 1988, 27, 1009.

3. Weber, E.; Vögtle, F. Host-Guest Complex Chemistry. Springer-Verlag, Berlin, 1982.

4. Lehn, J. M. Supramolecular Chemistry, Concepts and Perspectives. VCH Publ., Weinheim, 1995.

5. Uhlenheuer, D.A.; Petkau, K.; Brunsveld, L. Chem. Soc. Rev. 2010, 39, 2817.

6. Pandoli, O.; Spada, G. P. J. Inclusion Phen. Macrocycl. Chem. 2009, 65, 205.

7. Pedersen, C. J. J. Am. Chem. Soc. 1967, 89, 7017.

8. Meeuwissen, J.; Reek, J. N. H. Nature, Chem. 2010, 2, 615.

9. Maksimov, A. L.; Sakharov, D. A.; Filippova, T. Y.; Zhuchkova, A. Y.; Karakhanov, E. A. Ind. Eng. Chem. Res. 2005, 44, 8644.

10. Ionita, G.; Ionita, P. J. Inclusion Phen. 2003, 45, 79.

11. Ionita, P.; Caproiu, M. T.; Caldararu, H.; Ionita, G. Rev. Roum. Chim. 2001, 46, 363.

12. Bem, M.; Caproiu, M. T.; Vasilescu, M.; Tudose, M.; Socoteanu, R.; Nicolae, A.; Constantinescu, T.; Banciu, M. D. Rev. Roum. Chim. 2003, 48, 709.

13. Radutiu, A. C.; Baciu, I.; Caproiu, M. T.; Ionita, P.; Covaci, I. C.; Constantinescu, T. Rev. Roum. Chim. 2005, 50, 341.

14. Minkin, V. I.; Dubonosov, A. D.; Bren, V. A.; Tsukanov, A. V. Arkivoc 2008, (iv), 90.

15. Ocak, U.; Ocak, M.; Basoglu, A.; Parlayan, S.; Alp, H.; Kantekin, H. J. Incl. Phenom. Macrocycl. Chem. 2010, 67, 19.

16. Inerowicz, H. D. J. Incl. Phenom. Macrocycl. Chem. 2001, 39, 211.

17. Zeng, W.; Mao, Z. H.; Gong, M.; Zhang, C. C.; Qin, S. Y.; Su, J. Chinese Chem. Lett. 2003, $14,786$.

18. Kima, J.; Seoc, E.; Kimd, S.; Parke, S.; Kimf, B. Sensors Actuators B 2008, 134, 843.

19. Mandal, A. K.; Suresh, M. E.; Suresh, S.; Mishra, K.; Mishra, S.; Das, A. Sensors Actuators B 2010, 145, 32 .

20. Marques de Oliveira, I. A.; Risco, D.; Vocanson, F.; Crespo, E.; Teixidor, F.; Zine, N.; Bausells, J.; Samitier, J.; Errachid, A. Sensors Actuators B 2008, 130, 295.

21. Covaci, I. C.; Constantinescu, T.; Caproiu, M. T.; Draghici, C.; Ionita, P.; Luca, C.; Stanciuc, G.; Maganu, M.; Balaban, A. T. Rev. Roum. Chim. 1999, 44, 333. 
22. Covaci, I. C.; Constantinescu, T.; Caproiu, M. T.; Dumitrascu, F.; Luca, C.; Balaban, A. T. Rev. Roum. Chim. 1999, 44, 531.

23. Covaci, I. C.; Ionita, P.; Caproiu, M. T.; Caproiu, M. T.; Socoteanu, R.; Constantinescu, T.; Balaban, A. T. Centr. Eur. J. Chem. 2003, 1, 57.

24. Klopman, K.; Tsuda, J.B.; Louis, R. E.; Davis, R. Tetrahedron 1970, 26, 4549.

25. Tudose, M.; Badea, F.; Ionita, G.; Maganu, M.; Caproiu, M. T.; Ionita, P.; Constantinescu, T.; Balaban, Struct. Chem. 2010, 21, 1227.

26. Luca, C.; Ionita, P.; Popa, E.; Constantinescu, T. Rev. Roum. Chim. 1998, 43, 753.

27. Lamb, J. D.; Christensen, J.; Izatt, S. R.; Astin, M.S.; Izatt, R. M. J. Am. Chem. Soc. 1980, $102,3399$.

28. Inoue,Y.; Amano, F.; Okada, N.; Liu, Y.; Tong, L. H. J. Chem. Soc., Perkin Trans. 21990 , 1239.

29. Bourson, J.; Pouget, J.; Valeur, B. J. Phys. Chem. 1993, 97, 4552.

30. Hilgenfeld , R.; Saenger, W; Paintel, G. R.; Pressman , B. C.; Kellogg, R. M.; Montanari, F.; Landini, D.; Rolla, F. Host-Guest Complex Chemistry II, Akademie-Verlag, Berlin, 1982.

31. 31.Vögtle, F., Supramolecular Chemistry, Wiley: Chichester, 1991.

32. www.hyper.com/products/evaluation/hyper75/default.html.

33. Tudose, M.; Ionita, P.; Dumitrascu, F.; Draghici, C.; Caproiu, M. T.; Covaci, I. C.; Constantinescu, T.; Banciu, M. D.; Balaban, A. T. Arkivoc 2005, (iv), 225. 